\title{
ORIGINAL
}

ARTICLES

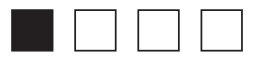

\section{Gender Concordance of First and Senior Authors in Family Medicine Journals}

Alexa Mieses Malchuk, MD, MPH; Megan Coffman, MS; Elizabeth Wilkinson; Yalda Jabbarpour, MD

\begin{abstract}
BACKGROUND AND OBJECTIVES: Women have increased in presence within academic family medicine over time yet remain underrepresented among senior faculty. Mentorship is a mechanism by which senior faculty support scholarly achievements, accelerating advancement of junior faculty.
\end{abstract}

METHODS: We analyzed 10 years (2008-2017) of original research articles in three peer-reviewed family medicine journals. We examined first author/last author pairs by gender as a proxy for mentorship of junior faculty by senior faculty. We compiled family medicine faculty data across 9 years to compare trends in scholarly mentorship with faculty advancement.

RESULTS: Female last authorship increased from $28.8 \%(55 / 191)$ of original research articles with a first and last author in 2008 to $41.8 \%(94 / 225)$ in 2017. The share of female first authors on articles with a female last author was $56.4 \%$ in $\mathbf{2 0 0 8}$ and 2017 . The share of female first authors on articles with a male last author increased from $41.2 \%(56 / 136)$ to $55.7 \%(73 / 131)$ between 2008 and 2017. From 2009-2017, the proportion of women increased for assistant, associate, and full professor roles, but remained under $50 \%$ for the associate professor role and at 35\% for professorship in 2017.

CONCLUSIONS: Despite disproportionate rates of last authorship and senior faculty positions in family medicine departments, senior female authors have equal if not greater rates of mentorship of female first authors in family medicine literature. The increase in first authorship, last authorship, and faculty position indicates that improvements have occurred in gender advancement over the study period, but gains are still needed to improve gender equity within the field.

(Fam Med. 2021;53(2):92-7.)

doi: 10.22454/FamMed.2021.355251

$\mathbf{T}$ hough the rates of women in academic medicine continue to increase, gender disparities persist. Women remain underrepresented as authors in the peer-reviewed academic medical literature and in leadership roles. Within family medicine, one of the largest physician specialties, less than $40 \%$ of professors are women, and fewer than half of first and last authors in major family medicine journals are women, although their presence is increasing. ${ }^{1-3}$ The presence of female leaders to serve as mentors and role models is important in the institutional advancement of women in academic medicine. Mentorship broadly refers to the "dynamic reciprocal relationship between an advanced career incumbent (the mentor) and a gé) aimed at fostering the development of the junior person/protégé."4 junior faculty member (the proté-
Mentoring may also be confined to one aspect of career development such as scholarly publication only. In gynecology, for example, peer-reviewed scientific papers with senior female authors were more likely to have female first authors, suggesting a mentorship role. ${ }^{5}$ This study examines first author/last author pairs in peer-reviewed articles to observe whether differential rates in mentorship exist between male and female authors in academic family medicine.

Female matriculation into medical school has greatly increased over the years. Just $5.5 \%$ of medical students were female in 1950 compared to $47 \%$ in $2014 .{ }^{6}$ In the $2019-2020$ academic year, $52 \%$ of the matriculants of US medical schools were female. ${ }^{7}$ In concordance with this, the proportion of women in the physician workforce has grown from $6 \%$ in 1950 to $36 \%$ in $2015 .{ }^{6}$ Despite the rising number of women in medicine, disparities in female representation exist in different fields including academic medicine, which encompasses all medical specialties.

The Association of American Medical Colleges (AAMC) found that 75,108 women were full-time faculty in 2018 compared to 103,435 male faculty. ${ }^{8}$ Of the female faculty, $12.9 \%$ were full professors whereas

From the Department of Family Medicine, University of North Carolina-Chapel Hill (Dr Malchuk); and the Robert Graham Center for Policy Studies in Family Medicine and Primary Care, Washington, DC (Dr Jabbarpour, and Mss Coffman and Ms Wilkinson). 
$27.6 \%$ of male faculty were full professors. ${ }^{8}$ In family medicine, there were 5,263 full-time medical school faculty in the United States in 2017. Of the 736 with full professor rank, 265 were women $(36.0 \%) .{ }^{1}$ The cause of these disparities is undoubtedly complex and multifactorial. However, a possible factor may relate to one specific aspect of academic medicine: scholarly publication.

Several studies have found major differences between men and women publishing in peer-reviewed scientific literature across academic medicine. These differences have ranged from women being underrepresented in leadership roles to women being less likely to compose or publish manuscripts. ${ }^{9-13}$ In family medicine, female authorship in three major family medicine journals has increased in the last decade, but there is still a gender gap in senior authorship. ${ }^{14}$

Gender differences in scholarship are relevant to the gender gap among academic senior faculty positions. ${ }^{15}$ Scholarship is a key component of faculty appointment and promotion. The importance of generating new knowledge is clear when reviewing institutions' academic promotion handbooks. ${ }^{16}$ This includes publication in peer-reviewed journals, with article first authorship given significant weight. In academic medicine, the last listed author is usually reserved for the most senior person on the project. Further, it is typical for the most senior person on the team to act as a mentor to the team, including to the first author. Mentorship is often helpful in ensuring more junior researchers have a productive career. ${ }^{17}$

Given the evidence of inequity in leadership among women in academic medicine, mentorship of female junior faculty is especially important. Mentorship has been proven to result in higher satisfaction and retention of women in academic medicine. ${ }^{18,19}$ Shared experiences and role modeling are important in the mentor-mentee relationship. A study of National Institutes of Health K08 and K12 award winners found that mentees with gender-concordant mentor-mentee pairs reported higher rates of viewing their mentor as a role model. Female respondents in the study reported higher rates of issues with work-life balance overall, and all respondents reported that female mentors were more likely to give advice on work-life balance. ${ }^{20}$

This study examines whether female senior authors are more likely to publish with female first authors in high-impact family medicine journals over a 10 -year period. Additionally, we examine female representation in family medicine faculty positions. This investigation fills a gap in the literature regarding publication and mentorship among women in academic family medicine.

\section{Methods}

\section{Data Source}

We used publicly available data from Ovid Medline to obtain all articles published in 2008-2017 in Annals of Family Medicine, the Journal of the American Board of Family Medicine, and Family Medicine. We excluded American Family Physician because a majority of the articles are classified as review articles as opposed to original research. Medline organizes articles into over 100 different categories. We developed exclusion terms to narrow our search results to original research. For example, we excluded terms such as "editorial" and "news." See Supplemental Digital Appendix 1 (https://journals.stfm. org/media/3613/supplemental-digitalappendix-1-wilkinson.pdf) for a full list of exclusion terms.

We used publicly available data from AAMC that includes proportion of female faculty and rank specific to the field of family medicine for various years. We found complete data for years 2009, 2012, 2015, and 2017, which overlapped with years for which we collected authorship data. $^{2,17-19}$

\section{Measures}

We determined the gender for first and last authors listed on articles from our search. This is aligned with other published bibliometric analyses that examined gender differences in authorship. ${ }^{24,25}$ For articles with only one author, we counted that author as first author. This is aligned with the commonly accepted idea in academia that the first author is traditionally the author that contributed most significantly. Some articles from our search included an organization as a last author, for example a sponsoring organization that provided funding; in this case, we counted the individual author listed last as "last author."

\section{Analysis}

For all sample years 2008-2017, we ran names of first and last authors through a program developed at the Robert Graham Center that assigns gender using US Social Security birth records from 1950 to 2000 combined with a world-wide name dictionary. We coded names as male or female if they had been assigned to the respective gender in at least $60 \%$ of instances in the US Social Security records. The gender for names that could not be identified via the automatic coding were manually assigned using two rounds of reviews by study authors with a third round of reconciliation, conducted through Google searches and examination of institutional websites.

We verified the accuracy of this novel program by conducting manual assignment for all even-numbered years. Two reviewers separately labeled first and last author gender using listed first name. The two reviewers conducted web searches to find pictures or gender-identifying pronouns, and a third reviewer resolved any differences between reviewers 1 and 2 . We compared manual assignment and automated assignment for the even sample years and found a $98.4 \%$ match rate for first author gender and a $98.0 \%$ match rate for last author gender.

\section{Statistical Analyses}

We calculated the proportion of publications with male or female first authors by gender of the last author. 
We repeated this for each year from 2008-2017 and for the overall sample. We used a $\chi^{2}$ test to observe differences in first author gender by last author gender. We used the Cochran-Armitage trend test to measure the significance in the proportional trends over time for gender composition by faculty position. Significance was set at a $P$ value of .05. We used Stata (version 14.2, Stata Corp, College Station, Texas) for analysis. The American Academy of Family Physicians Institutional Review Board determined this study was exempt from formal review.

\section{Results}

\section{Sample}

The initial sample included 2,644 articles deemed original research. The gender of the first author could not be identified for 103 publications
(103/2,644, 3.9\%) using the automated program. For the 2,245 publications with a last author, gender of the last author could not be identified for 198 publications (198/2,245, $6.6 \%)$; of these, 67 had institutions listed as the last author $(67 / 2,245$, $3.0 \%$ ) and the remaining 131 publications were not identified due to undetermined gender (131/2,245, 5.8\%). After hand-checking and reconciliation, we identified seven additional articles that had only one author and were removed from the last author count $(7 / 2,245,0.3 \%)$. We could not identify the gender for 11 first authors $(11 / 2,644,0.4 \%)$ and 11 last authors $(11 / 2,238,0.5 \%)$ in a total of 21 articles (one article had both first and last author unidentified). We removed 400 articles that only had one listed author. The final sample had 2,223 original research articles with a first and last author (Digital Supplemental Appendix 2: https:// journals.stfm.org/media/3614/supplementaldigitalappendix2-wilkinson.pdf).

\section{Mentorship Pairs}

Female first authorship of any article with a last author increased from 45.5\% (87/191) of articles studied in 2008 to $56.0 \%(126 / 225)$ in 2017 $(P<.01)$. Female last authorship increased from $28.8 \%$ (55/191) of articles in 2008 to $41.8 \%$ (94/225) of articles in $2017(P<.01)$. Overall, articles with a male last author had a female first author $43.9 \%$ of the time (599/1,366), while articles with a female last author had a female first author $55.4 \%$ of the time (475/857, $P<.01$; Table 1). Of articles with male senior authors, the share of female first authors increased from $41.2 \%$

Table 1: First Author Gender by Last Author Gender of Peer-Reviewed Articles Published in High-Impact Family Medicine Journals, 2008-2017

\begin{tabular}{|c|c|c|c|c|c|}
\hline \multirow{3}{*}{ Year } & \multirow{3}{*}{ Last Author Gender } & & Author Gen & & \multirow{3}{*}{$P$ Value $\left(\chi^{2}\right)$} \\
\hline & & Male & Female & Total & \\
\hline & & \multicolumn{3}{|c|}{ n (\%) } & \\
\hline \multirow{3}{*}{2008} & Male & $80(58.8)$ & $56(41.2)$ & $136(100)$ & \multirow{3}{*}{.056} \\
\hline & Female & $24(43.6)$ & $31(56.4)$ & $55(100)$ & \\
\hline & Total & $104(54.5)$ & 87 (45.5) & $191(100)$ & \\
\hline \multirow{3}{*}{2009} & Male & $63(51.2)$ & $60(48.8)$ & $123(100)$ & \multirow{3}{*}{.325} \\
\hline & Female & $41(58.6)$ & $29(41.4)$ & $70(100)$ & \\
\hline & Total & $104(53.9)$ & $89(46.1)$ & $193(100)$ & \\
\hline \multirow{3}{*}{2010} & Male & $90(61.6)$ & $56(38.4)$ & $146(100)$ & \multirow{3}{*}{.303} \\
\hline & Female & $38(54.3)$ & $32(45.7)$ & $70(100)$ & \\
\hline & Total & $128(59.3)$ & $88(40.7)$ & $216(100)$ & \\
\hline \multirow{3}{*}{2011} & Male & $80(63.0)$ & $47(37.0)$ & $127(100)$ & \multirow{3}{*}{.497} \\
\hline & Female & $49(58.3)$ & $35(41.7)$ & $84(100)$ & \\
\hline & Total & $129(61.1)$ & $82(38.9)$ & 211 (100) & \\
\hline \multirow{3}{*}{2012} & Male & $93(62.8)$ & $55(37.2)$ & $148(100)$ & \multirow{3}{*}{.006} \\
\hline & Female & $41(44.6)$ & $51(55.4)$ & $92(100)$ & \\
\hline & Total & $134(55.8)$ & 106 (44.2) & $240(100)$ & \\
\hline \multirow{3}{*}{2013} & Male & $76(56.7)$ & $58(43.3)$ & $134(100)$ & \multirow{3}{*}{.062} \\
\hline & Female & $42(44.2)$ & $53(55.8)$ & $95(100)$ & \\
\hline & Total & $118(51.5)$ & $111(48.5)$ & 229 (100) & \\
\hline
\end{tabular}


Table 1: Continued

\begin{tabular}{|c|c|c|c|c|c|}
\hline \multirow{3}{*}{ Year } & \multirow{3}{*}{ Last Author Gender } & & t Author Gend & & \multirow{3}{*}{$P$ Value $\left(\chi^{2}\right)$} \\
\hline & & Male & Female & Total & \\
\hline & & \multicolumn{3}{|c|}{ n (\%) } & \\
\hline \multirow{3}{*}{2014} & Male & $72(53.3)$ & $63(46.7)$ & $135(100)$ & \multirow{3}{*}{.514} \\
\hline & Female & $43(48.9)$ & $45(51.1)$ & $88(100)$ & \\
\hline & Total & $115(51.6)$ & $108(48.4)$ & $223(100)$ & \\
\hline \multirow{3}{*}{2015} & Male & $81(55.5)$ & $65(44.5)$ & $146(100)$ & \multirow{3}{*}{.001} \\
\hline & Female & $40(35.1)$ & $74(64.9)$ & $114(100)$ & \\
\hline & Total & $121(46.5)$ & 139 (53.5) & $260(100)$ & \\
\hline \multirow{3}{*}{2016} & Male & $74(52.9)$ & $66(47.1)$ & $140(100)$ & \multirow{3}{*}{.000} \\
\hline & Female & $23(24.2)$ & $72(75.8)$ & $95(100)$ & \\
\hline & Total & $97(41.3)$ & $138(58.7)$ & 235 (100) & \\
\hline \multirow{3}{*}{2017} & Male & $58(44.3)$ & $73(55.7)$ & $131(100)$ & \multirow{3}{*}{.922} \\
\hline & Female & $41(43.6)$ & $53(56.4)$ & $94(100)$ & \\
\hline & Total & $99(44.0)$ & $126(56.0)$ & $225(100)$ & \\
\hline \multirow{3}{*}{ Total } & Male & 767 (56.1) & 599 (43.9) & 1,366 (100) & \multirow{3}{*}{.000} \\
\hline & Female & 382 (44.6) & $475(55.4)$ & $857(100)$ & \\
\hline & Total & $1,149(51.7)$ & 1,074 (48.3) & 2,223 (100) & \\
\hline
\end{tabular}

Source: Annals of Family Medicine, Journal of the American Board of Family Medicine, Family Medicine, 2008-2017.

Figure 1: Percent of Peer-Reviewed Articles in Three HighImpact Family Medicine Journals With a Female First Author by Gender of Last Author, 2008 Through 2017

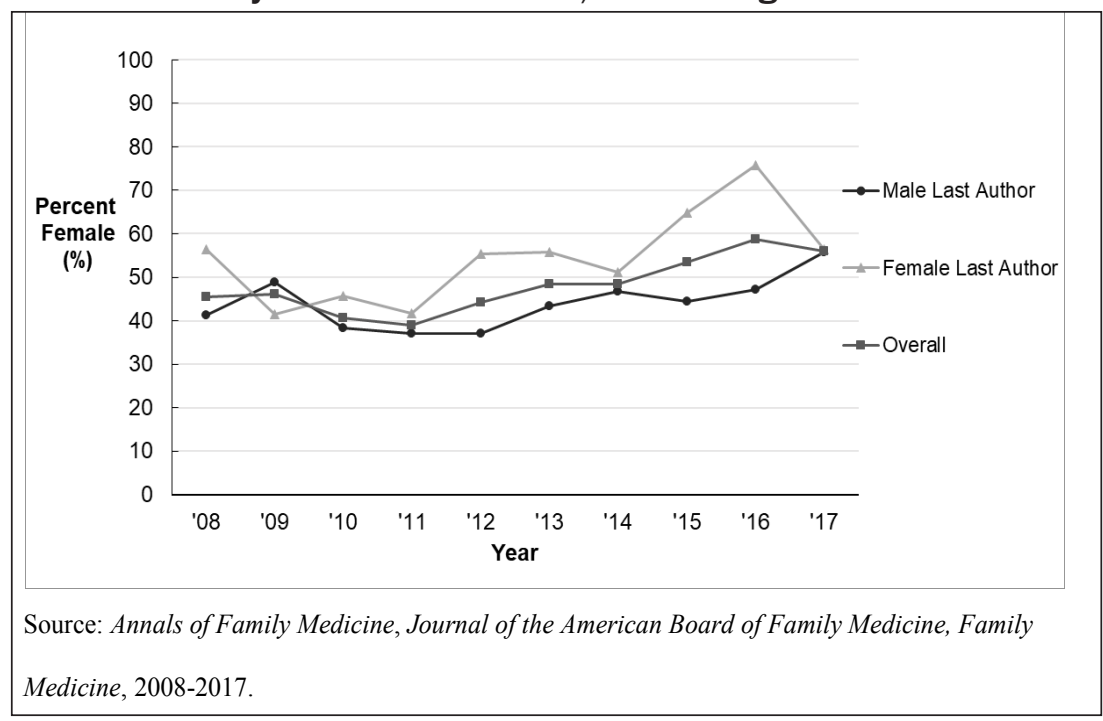

(56/136) in 2008 to $55.7 \%(73 / 131)$ in $2017(P=.02$; Figure 1). Of articles with female senior authors, the share of articles with female first authors remained unchanged at $56.4 \%$ at the start and end periods of 2008 and 2017 (31/55 and 53/94, respectively); however, the overall upward trend was significant $(P<.01)$.

\section{Faculty}

Female family medicine faculty with the roles of assistant, associate, or full professor increased from $40.9 \%$
$(1,549 / 3,790)$ overall in 2009 to $48.5 \%(2,406 / 4,959)$ in $2017(P<.01$; Table 2, Figure 2). By academic rank, the share of family medicine faculty comprised of women increased from 2009 to 2017 for assistant, associate, and full professor rank $(P<.01$ for each rank), but the share of women in the associate professor or professor role remained below $50 \%$ in the time period (Table 2, Figure 2).

\section{Discussion}

Our findings show that from 20082017, among authors of original research published in major academic family medicine journals, female last authors were more likely to have published an article with a female first author than male last authors. This indicates that there may be a gender concordant mentorship linkage. This could be explained by multiple factors. For example, female junior faculty may have sought female-led research projects, or female senior faculty may have sought to mentor female junior faculty. Yet, a desire for gender concordance in the 
Table 2: Female Faculty in US Medical School Family Medicine Departments by Faculty Rank, 2009-2017

\begin{tabular}{|l|c|c|c|c|c|}
\hline \multicolumn{7}{|c|}{ Faculty Rank } & 2009 & $\mathbf{5}$ & $\mathbf{2 0 1 5}$ & $\mathbf{2 0 1 7}$ & $\boldsymbol{P}$ Value \\
\hline \multicolumn{7}{|c|}{ n/N (\%) } \\
\hline Assistant professor & $1,104 / 2,334(47.3)$ & $1,173 / 2,323(50.5)$ & $1,586 / 3,116(50.9)$ & $1,700 / 3,249(52.3)$ & .001 \\
\hline Associate professor & $288 / 846(34.0)$ & $368 / 932(39.5)$ & $420 / 969(43.3)$ & $450 / 978(46.0)$ & .001 \\
\hline Professor & $157 / 610(25.7)$ & $176 / 673(26.2)$ & $218 / 703(31.0)$ & $256 / 732(35.0)$ & .001 \\
\hline Total & $\mathbf{1 , 5 4 9 / 3 , 7 9 0 ( 4 0 . 9 )}$ & $\mathbf{1 , 7 1 7 / 3 , 9 2 8 ( 4 3 . 7 )}$ & $\mathbf{2 , 2 2 4 / 4 , 7 8 8 ( 4 6 . 5 )}$ & $\mathbf{2 , 4 0 6 / 4 , 9 5 9 ( 4 8 . 5 )}$ & $\mathbf{. 0 0 1}$ \\
\hline
\end{tabular}

\section{Figure 2: Percent of Family Medicine Faculty Female by Faculty Position, 2009-2017}

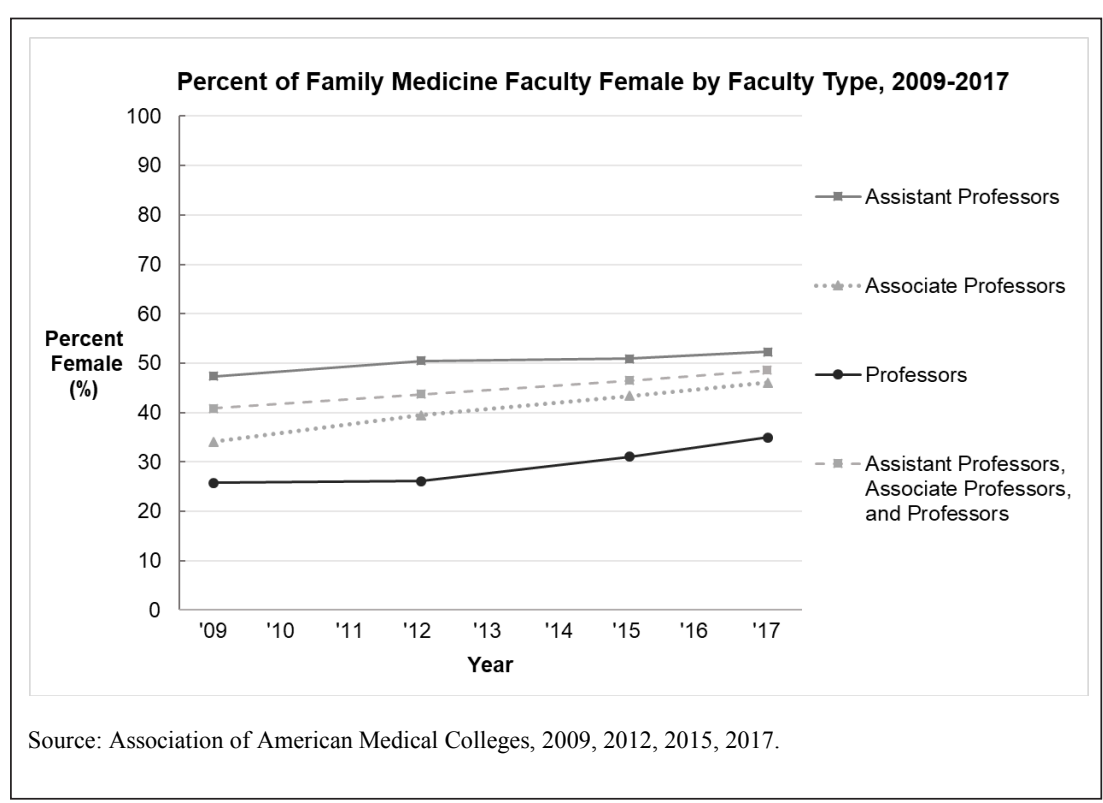

mentorship relationship does not explain our findings completely, since although male last authors were less likely to have a female first author on their publication, the rate of male last authors with female first authors also increased throughout the study period. It could be that our findings simply represent the fact that female first authorship is growing over time, while female last authorship has remained relatively flat. The question then becomes why is female last authorship not increasing at the same rate; if last authorship is a proxy for senior faculty, what can universities do to foster faculty advancement for females? More study of the mechanisms of mentorship within family medicine departments is warranted. However, the rate of male last authors with female first authors increased throughout the study period to match the rate of female last authors, suggesting there is also an increase of mentorship of female junior faculty among male senior faculty.

Meanwhile, the number of female first authors increased over the study period. Concordant with that increase, the number of both male senior authors paired with female first authors increased. There was an unexpected initial upswing of female-female pairs followed by a steep drop off from 2016 to 2017. The reason for this is unclear. One possibility is that since there are more male senior authors to begin with, they are responsible for mentoring an increasing number of female first authors. Data for a longer time period is necessary to account for annual fluctuations.

Regarding academic faculty in family medicine departments, rates of women in full professorship are increasing over time, but hace not yet reached $50 \%$. Given that a large proportion of scholarship in the form of peer-reviewed publications occurs in the academic setting, it is important to consider the makeup of these institutions when conducting a bibliometric analysis of this kind. Overrepresentation of males among senior family medicine faculty may help explain why female first authors paired with senior male authors appears to have increased over time.

This study has several limitations. First, whether or not first author/ last author pairs can be used as a proxy for mentorship is logical but debatable. However, others have suggested it may be a fair proxy. ${ }^{5}$ While the last author is often the most senior and most directive throughout the publication process, that author may not be the person providing the most impactful mentorship to others in the research group (nor the person providing mentorship around issues apart from scholarly publication). More evidence is needed to determine actual physician-researcher attitudes and beliefs around mentoring, especially because academic clinical departments may have different attitudes compared with traditional biomedical departments. Second, the study covered a 10 year period. Going back further in history may lead to different observable trends. It would be helpful to continue to collect this data moving forward to observe future trends. Third, 
while the three journals studied are family medicine journals, given the breadth of the specialty, family medicine researchers are publishing in other journals. Conversely, these staple family medicine journals also include researchers from other specialties related to primary care, not just family medicine. Regardless of these limitations, these three journals are high-impact and used by family physicians and departments on a regular basis and are thus still representative of the field.

Many studies have examined the gender gap in authorship, ${ }^{9-15,20,21}$ and literature on gendered experiences in medicine and academia point to mentorship of women as one possible solution to address gender disparities in the field. ${ }^{18}$ Although mentorship from any gender is important, there is also literature suggesting that it is important for early-career women to see other women in leadership and mentorship positions. ${ }^{26}$ Academic institutions and researchers need to be attentive to these trends in senior female mentorship of junior women. As we work toward closing the gender gap in academic medicine, it is important for institutions to foster environments that allow for the advancement of women, including mentorship by other women.

ACKNOWLEDGMENTS: The authors thank Emily Bassett, Andrew Bazemore, Stephen Petterson, Anuradha Jetty, Hoon Byun, and YoonKyung Chung.

CORRESPONDING AUTHOR: Address correspondence to Dr Alexa Mieses Malchuk, UNC Family Medicine at Durham, 3708 Mayfair St, Suite 100, Durham, NC 27707. 984-215-4780. alexa_mieses@med.unc.edu.

\section{References}

1. Association of American Medical Colleges. AAMC Faculty Roster, December 31, 2018, snapshot as of December 31, 2019. Table 13: US Medical School Faculty by Sex, Rank, and Department, 2018. https://www.aamc.org/system/files/2020-01/2018Table13.pdf. Accessed October 2, 2020

2. Schrager S, Bouwkamp C, Mundt M. Gender and first authorship of papers in family medicine journals 2006-2008. Fam Med. 2011;43(3):155-159.
3. Association of American Medical Colleges AAMC Faculty Roster, December 31, 2017 snapshot as of December 31, 2019. Table 13: U.S. Medical School Faculty by Sex, Rank, and Department, 2017. https://www.aamc.org/system/files/2020-01/2017Table13.pdf. Accessed October 2, 2020.

4. Palepu A, Friedman RH, Barnett RC, et al. Junior faculty members' mentoring relationships and their professional development in U.S. medical schools. Acad Med. 1998;73(3):318-323. doi:10.1097/00001888-199803000-00021

5. Penn CA, Ebott JA, Larach DB, Hesson AM, Waljee JF, Larach MG. The gender authorship gap in gynecologic oncology research. Gynecol Oncol Rep. 2019;29:83-84. doi:10.1016/j. gore.2019.07.011

6. Staff Care. Women in Medicine: A Review of Changing Physician Demographics, Female Physicians by Specialty, State and Related Data. 2015. https://www.amnhealthcare.com/ uploadedFiles/MainSite/Content/Staffing_Recruitment/Staffcare-WP-Women $\% 20 \mathrm{in} \% 20$ Med.pdf. Accessed October 2, 2020.

7. Association of American Medical Colleges. 2018 FACTS: Applicants and Matriculants Data. https://www.aamc.org/data-reports/students-residents/interactive-data/2018-factsapplicants-and-matriculants-data. Accessed October 2, 2020.

8. Association of American Medical Colleges. Faculty Roster: US Medical School Faculty 2018. https://www.aamc.org/data-reports/faculty-institutions/interactive-data/data-reports/ faculty-institutions/interactive-data/2018-usmedical-school-faculty. Accessed October 2, 2020.

9. Macaluso B, Larivière V, Sugimoto T, Sugimoto CR. Is science built on the shoulders of women? A study of gender differences in contributorship. Acad Med. 2016;91(8):1136-1142. doi:10.1097/ACM.0000000000001261

10. Amering M, Schrank B, Sibitz I. The gender gap in high-impact psychiatry journals. Acad Med. 2011;86(8):946-952. doi:10.1097/ ACM.0b013e3182222887

11. Penn CA, Ebott JA, Larach DB, Hesson AM, Waljee JF, Larach MG. The gender authorship gap in gynecologic oncology research. Gynecol Oncol Rep. 2019;29:83-84. doi:10.1016/j. gore.2019.07.011

12. Kim C-Y, Sivasundaram L, Trivedi NN, et al. A 46-year analysis of gender trends in academic authorship in orthopaedic sports medicine. J Am Acad Orthop Surg. 2019;27(13):493-501. doi:10.5435/JAAOS-D-18-00669

13. Jagsi R, Guancial EA, Worobey CC, et al. The "gender gap" in authorship of academic medical literature - a 35-year perspective. N Engl J Med. 2006;355(3):281-287. doi:10.1056/ NEJMsa053910

14. Jabbarpour Y, Wilkinson E, Coffman M, Mieses A. Has female authorship distribution in family medicine research evolved over time? Ann Fam Med. in press.

15. Carr PL, Raj A, Kaplan SE, Terrin N, Breeze JL, Freund KM. Gender differences in academic medicine: retention, rank, and leadership comparisons from the National Faculty Survey. Acad Med. 2018;93(11):1694-1699. doi:10.1097/ ACM.0000000000002146
16. Feder ME, Madara JL. Evidence-based appointment and promotion of academic faculty at the University of Chicago. Acad Med. 2008;83(1):85-95. doi:10.1097/ ACM.0b013e31815c64d5

17. Sambunjak D, Straus SE, Marusi冈 A. Mentoring in academic medicine: a systematic review. JAMA. 2006;296(9):1103-1115. doi:10.1001/ jama.296.9.1103

18. Farkas AH, Bonifacino E, Turner R, Tilstra SA, Corbelli JA. Mentorship of women in academic medicine: a systematic review. J Gen Intern Med. 2019;34(7):1322-1329. doi:10.1007/ s11606-019-04955-2

19. Palepu A, Friedman RH, Barnett RC, et al. Junior faculty members' mentoring relationships and their professional development in U.S. medical schools. Acad Med. 1998;73(3):318-323. doi:10.1097/00001888-199803000-00021

20. DeCastro R, Griffith KA, Ubel PA, Stewart A, Jagsi R. Mentoring and the career satisfaction of male and female academic medical faculty. Acad Med. 2014;89(2):301-311. doi:10.1097/ ACM.0000000000000109

21. Leadley J. Women in U.S. Academic Medicine: Statistics and Benchmarking Report, 20082009. Washington, DC:Association of American Medical Colleges; 2009.

22. Jolliff L, Leadley J, Coakley E, Sloane RA. Women in U.S. Academic Medicine and Science: Statistics and Benchmarking Report, 2011-2012. Washington, DC: Association of American Medical Colleges; 2012.

23. Association of American Medical Colleges. AAMC Faculty Roster, December 31, 2015 snapshot. Table 3: Distribution of Full-Time Faculty by Department, Rank, and Gender, 2015. https://www.aamc.org/system/files/ reports/1/2015table3.pdf. Accessed October 2, 2020.

24. Fishman M, Williams WA II, Goodman DM, Ross LF. Gender differences in the authorship of original research in pediatric journals, 2001-2016. J Pediatr. 2017;191:244-249.e1. doi:10.1016/j.jpeds.2017.08.044

25. Filardo G, da Graca B, Sass DM, Pollock BD, Smith EB, Martinez MA-M. Trends and comparison of female first authorship in high impact medical journals: observational study (1994-2014). BMJ. 2016;352(March):i847. doi:10.1136/bmj.i847

26. Kosoko-Lasaki O, Sonnino RE, Voytko ML. Mentoring for women and underrepresented minority faculty and students: experience at two institutions of higher education. J Natl Med Assoc. 2006;98(9):1449-1459. 